\title{
Research progress on siRNA delivery with nonviral carriers
}

\author{
This article was published in the following Dove Press journal: \\ International Journal of Nanomedicine \\ II May 20I I \\ Number of times this article has been viewed
}

\author{
Yan Gao* \\ Xin-Ling Liu* \\ Xiao-Rong Li \\ Tianjin Medical University Eye Center, \\ Tianjin, China \\ *These two authors contributed \\ equally to this work.
}

Correspondence: Xiao-Rong Li

No. 25I FuKang Road,

NanKai Distinct, Tianjin 300384,

People's Republic of China

$\mathrm{Tel}+8602258280810$

Fax +86022 23346434

Email xiaorongli@medmail.com
Abstract: RNA interference is a powerful method for the knockdown of pathologically relevant genes. Small interfering RNAs (siRNAs) have been widely demonstrated as effective biomedical genetic-therapy applications for many diseases. Unfortunately, siRNA duplexes are not ideal drug-like molecules. Problems hindering their effective application fundamentally lie in their delivery, stability, and off-target effects. Delivery systems provide solutions to many of the challenges facing siRNA therapeutics. Due to some fatal disadvantages of viral vectors, nonviral carriers have been studied extensively. Aside from liposomes, nanoparticles and cationic polymer carriers have exhibited improved in vivo stability, better biocompatibility, and efficiency for gene silencing with less cellular toxicity. They may represent a promising strategy for siRNA-based therapies, especially as nanomaterials. The present review also summarizes other methods of siRNA delivery and the side effects of the nanoparticles.

Keywords: small interfering RNA, nonviral vector, gene therapy, delivery system, nanoparticles, biocompatibility

\section{Introduction}

Since its discovery in 1998 by Fire et al, RNA interference (RNAi) has represented a promising new approach towards the inhibition of gene expression in vitro or in vivo. ${ }^{1-3}$ In 2001, Elbashir et $\mathrm{al}^{4}$ using synthetic small interfering RNA (siRNA), showed for the first time that RNAi also occurs in mammalian cell lines, making successful development of RNAi possible. Rapid progress in our understanding of RNAi-based mechanisms has led to the application of this powerful mechanism in the study of gene function, as well as therapeutic applications for disease treatment.

RNAi is mediated through approximately $21-23 \mathrm{nt}$, double-stranded siRNAs that trigger sequence-specific cleavage of mRNA molecules, leading to their subsequent degradation. ${ }^{5}$ These siRNAs are generated intracellularly through the cleavage of longer double-stranded RNAs, ${ }^{6,7}$ or are introduced into the cell as chemically synthesized siRNA molecules. ${ }^{4}$

However, the naked siRNA molecule, with negative charges, is susceptible to serum nucleases, renal clearance, and nontargeted biodistribution, making cellular target sites more difficult to access. Thus, it has many limitations, such as poor stability, short half-life, and low efficiency. The major hurdle faced by current RNAi therapeutic strategies is the efficiency of the delivery system. Recently, viral delivery, such as lentivirus and adenovirus delivery, of DNA-based siRNA constructs for RNAi-mediated vascular endothelial growth factor (VEGF) downregulation showed anti-neovascularization effects in various animal models..$^{8-10}$ Viral vectors are highly 
efficient delivery systems for nucleic acids; however, the potential for mutagenicity, limited loading capacities, high production costs, and most importantly, safety risks caused by their inflammatory and immunogenic effects severely limit the applicability of viruses. These concerns have led to the pursuit of nonviral alternatives. Thus, the direct, systemic, nonviral administration of siRNA molecules that allows for therapeutic use is most desirable. ${ }^{11}$ Nonviral vectors are capable of delivering nucleic acids, including genes, siRNA, or antisense RNA into cells, thus potentially resulting in their functional expression. These vectors are considered an attractive alternative for virus-based delivery systems. ${ }^{12}$

Multiple nonviral siRNA delivery systems include chemical modification of siRNA, liposomes, nanoparticles for siRNA delivery, cell-penetrating peptides, and targeted delivery. Positively charged cationic liposomes and polymers, such as polyethyleneimine, are currently the two major carriers used to complex with negatively charged siRNA for systemic delivery. ${ }^{13}$ Some of these novel vehicles can potentially overcome extracellular and intracellular barriers, and facilitate the site-specific delivery, cellular uptake, and intracellular target interactions of siRNA. ${ }^{14}$

The current review discusses the progress in the application of nonviral systems for synthetic RNAi molecule delivery, with focus on the characteristics and advantageous properties of siRNA nanoparticle systems.

\section{Chemical modification of siRNA}

The half-life of unmodified naked siRNAs in vivo ranges in minutes, but this can be significantly improved to hours by chemical modifications. ${ }^{15,16}$ In addition, chemical modification of siRNAs may enhance biological stability without adverse effects on the gene-silencing activity. Furthermore, modified siRNAs with superior potency reduces the dose required for gene silencing, ${ }^{10}$ and specific chemical modifications can minimize siRNA side effects, such as the induction of recipient immune responses and inherent off-targeting effects. ${ }^{17,18}$ Various chemical modifications to the backbone, nucleobases, terminals, and sugars of siRNAs have been reported so far, which are mainly focused on increasing its stability and enhancing its cellular uptake.

The most widely used siRNA modifications are on sugar moieties, which commonly include replacement of the $2^{\prime}$-fluoro (2'-F), 2'-O-methyl, 2'-halogen, $2^{\prime}$-amine, ${ }^{19}$ and locked nucleic acid (LNA), ${ }^{20}$ all of which have shown significant increase in siRNA serum stability. Layzer et $\mathrm{al}^{21}$ have demonstrated that siRNA modified with $2^{\prime}$-fluoro $\left(2^{\prime}-\mathrm{F}\right)$ pyrimidines are more functional in cell culture and have greatly increased stability and prolonged half-life (24 hours) in human plasma, compared with $2^{\prime}-\mathrm{OH}$ ( 1 minute) containing siRNAs. Jackson et $\mathrm{al}^{22}$ showed that $2^{\prime}$-O-methyl modifications to specific positions within the siRNA seed region reduces the number of off-target transcripts and the magnitude of their regulation, without significantly affecting the silencing of the intended targets.

The simplest approach to increase nuclease stability has been to modify the internucleotide phosphate linkage directly. ${ }^{23}$ Phosphorothioate $(\mathrm{P}=\mathrm{S})$ modifications can be placed in the RNA duplex easily at any desired position and will enhance the stability of siRNA in nuclease environments. Overhoff and Sczakiel stated that phosphorothioate (PTO)derived oligonucleotides stimulate the physical cellular uptake of siRNA in human cells. ${ }^{24}$ On the other hand, siRNAs with boranophosphonate $(\mathrm{P}=\mathrm{B})$ backbone modifications have much higher nuclease resistance than unmodified ones, with less cytotoxicity. In addition, Hall et $\mathrm{al}^{25}$ demonstrated that boranophosphate siRNAs are consistently more effective than siRNAs with the widely used phosphorothioate modification. Furthermore, boranophosphate siRNAs are at least 10 times more nuclease resistant than unmodified siRNAs. Therefore, the biochemical properties of boranophosphate siRNAs make them promising candidates for RNAi-based therapeutic applications. Recently, some groups used the same modified siRNA to treat patients with age-related macular degeneration (AMD). The process has reached Phase II clinical trials, and it was found to have no observable side effects. $^{26}$

To date, much of the focus has been on modifying the RNA backbone, and some laboratories have modified the siRNA bases that are centrally involved in target recognition. Terrazas and $\mathrm{Kool}^{27}$ explored the effects of methyl and propynyl substitution on siRNA duplex stability and cellular RNAi activity. The results suggested that smaller 5-methyl substitutions do not adversely affect gene-silencing activity; furthermore, this modification contributes positively to siRNA stability in human serum.

Terminal nucleotide modifications of the siRNA (also called siRNA conjugates) have also been reported as an efficient delivery strategy. These include peptide modification, such as transactivating transcriptional activator (TAT) peptide, cholesterol conjugation, folate, and aptamer conjugation, which offer opportunities to enhance pharmacological characteristics of or introduce special features to siRNA. ${ }^{28,29}$ Soutschek et $a 1^{30}$ reported that if both $5^{\prime}$ - and 3 -terminal modifications of the sense strand are well modified siRNAs, they could silence the endogenous gene 
that encodes apolipoprotein B after intravenous injection in mice.

Chemical modification of siRNA can increase the stability of the RNA duplex to nucleases, minimize the possibility of immunostimulatory responses, and decrease the possibility of off-target effects, as well as improve its pharmacodynamic properties and delivery to target cells. ${ }^{31}$ Chemical modification provides solutions to many of the challenges facing siRNA therapeutics, but the remaining challenge is to find universal chemical modification strategies, or to predict reliably which modifications will be effective for a given sequence. ${ }^{32}$

\section{Liposome-formulated delivery system}

Liposomes are probably the most extensively used materials for the delivery of gene molecules ever since their ability to transport the preproinsulin gene to the liver ${ }^{33}$ was demonstrated 25 years ago. Hence, their characteristics are outlined in detail. Liposomes, vesicles with an aqueous compartment enclosed in a phospholipid bilayer, can fuse with cell membranes and enhance drug delivery into cells. Polar drugs can be entrapped in their aqueous center. When lipids combine with nucleic acids to form amorphous particles, they are known as lipoplexes. ${ }^{34}$ siRNAs can either be entrapped within a lipid core ${ }^{35}$ or attached to the surface of the lipid materials ${ }^{36}$ for delivery. The liposome can protect nucleic acids from enzymatic degradation and deliver nucleic acids into cells by interacting with the negatively charged cell membrane. There are two kinds of liposome: neutral and cationic lipid material. Neutral liposomes confer low toxicity to mammalians with low transfection efficiency due to their surface charge. But cationic liposomes can cross the cell membrane and reach the target genes with good biocompatibility. ${ }^{37,38}$

There are two kinds of liposome, neutral and cationic, based on their lipid composition. Initially, neutral liposomes were used for in vitro and in vivo delivery of nucleic acids because of their low toxicity, low immunogenicity, and easy production. Halder et $\mathrm{al}^{39}$ examined the therapeutic potential of focal adhesion kinase (FAK)-siRNA in the neutral liposome 1,2-dioleoyl-sn-glycero-3-phosphatidylcholine (DOPC). The results show that treatment with FAK siRNADOPC results in decreased microvessel density, decreased expression of VEGF and matrix metalloproteinase-9, and increased apoptosis of tumor-associated endothelial cells and tumor cells.

Given that neutral liposomes confer low transfection efficiency due to their lack of surface charges, this methodology was soon supplanted when cationic liposomes were developed in $1989 .{ }^{40}$ The cationic charge can electrostatically combine with siRNA to achieve a more robust construct to improve cell entry and protect siRNA against serum degradation, whereas neutral lipids facilitate fusion with the host cell membrane. ${ }^{41}$ Spagnou et al ${ }^{37}$ selected a number of cationic liposome/lipid-based systems to investigate the optimum lipid to nucleic acid ratio, mode of delivery, biocompatibility, and dose-response effects. The results demonstrate that the systems mediate a maximal specific gene silencing and knockdown with significantly low toxicity to mammalians. Leal et $\mathrm{al}^{42}$ reported the development of cationic liposome (CL)-siRNA complexes with novel cubic phase nanostructures that exhibit efficient silencing at low toxicity. This finding underscored the importance of understanding the membrane-mediated interactions between the CL-siRNA complex nanostructure and cell components in developing CL-based genesilencing vectors.

Some cationic liposomes, such as Lipofectamine ${ }^{T M}$ 2000, Oligofectamine ${ }^{\mathrm{TM}}$, and Lipofectamine (Invitrogen), are commercially available. ${ }^{43}$ Huang $^{44}$ transfected two keratoepithelin (KE)-specific siRNAs into HEK293 cells via Lipofectamine to treat certain types of inherited corneal stromal dystrophy, and observed that KE expression is reduced by approximately $50 \%-80 \%$. Kim et $\mathrm{a}^{45}$ applied water-soluble lipopolymer (WSLP) for delivering siRNA targeting VEGF in vitro and in vivo, which significantly increased the efficiency of inhibition. WSLP/siRNA complexes can efficiently protect siRNAs from enzymatic degradation in serum-conditioned media.

Many researchers studied immunoliposomes to develop a vehicle that can be systemically administered safely and repeatedly, and will deliver the siRNA specifically and efficiently to the targeted tissues. Pirollo et al ${ }^{46}$ engineered a nanosized immunoliposome-based delivery complex that, when systemically administered, will preferentially target and deliver siRNA to tumor cells wherever they occur in the body. They enhanced the efficiency of this complex with the inclusion of a $\mathrm{pH}$-sensitive histidine-lysine peptide in the complex and by delivery of a modified anti-HER-2 siRNA molecule. The complex can sensitize human tumor cells to chemotherapeutics, silence the target gene, and inhibit tumor growth in a cancer model.

Successful lipoplex deliveries of siRNA has been reported in several studies, and mechanisms for the release of payload from lipoplexes have been suggested. Continued research into the mechanism of release may lead to the development 
of more bioresponsive vectors that can achieve higher levels of silencing for a given dose. ${ }^{47}$

\section{Nanotechnology-based siRNA delivery system}

The birth of nanotechnology has allowed people to transform nature at the molecular and atomic level, enabling the manipulation of single atoms. With the progress of material synthesis and the rise of nanotechnology, the synthesis of nanomaterials with specific functions has become possible. The development of nanotechnology in the biological area has made nanodelivery systems popular. Currently, nanospheres can smoothly pass the blood-brain barrier, testicle-blood barrier, and placenta. ${ }^{48,49}$ Thus, nanospheres will be suitable transfection carriers for improving the effect of gene therapy.

Due to their low toxicity, biodegradability, and biocompatibility, many nanomaterials are used as transfection carriers, such as chitosan, cyclodextrin, polyethyleneimine (PEI), poly(lactic-co-glycolic acid) (PLGA), dendrimers, magnetic nanoparticles, carbon nanotubes, and gold nanorods. Because of its high nuclease resistance and mucoadhesive properties, chitosan, natural polymers extracted from crustaceans, has become popular siRNA vectors. Howard et $\mathrm{al}^{50}$ used a chitosan-based siRNA nanoparticle delivery system for RNA interference in vitro and in vivo. They observed, using fluorescence microscopy, that Cy5-labeled nanoparticles were rapidly uptaken by NIH 3T3 cells within 1 hour and are accumulated over a 24-hour period. In vivo, effective RNAi was achieved in bronchiole epithelial cells of transgenic enhanced green fluorescent protein (EGFP) mice after nasal administration of chitosan/siRNA formulations. Ghosn et $\mathrm{al}^{51}$ reported the use of imidazole-modified chitosan-siRNA nanoparticles to mediate gene silencing via either intravenous or intranasal administration. The results showed that intravenous delivery demonstrated significant knockdown of glyceraldehyde 3-phosphate dehydrogenase (GAPDH) enzymes in both the lungs and the liver at as low as $1 \mathrm{mg} / \mathrm{kg}$ siRNA dose. For intranasal delivery, significant silencing of GAPDH protein expression was seen in the lungs with only $0.5 \mathrm{mg} / \mathrm{kg} /$ day siRNA delivered over three consecutive days.

As a cationic polymer, PEI with its high-density charge, which can protect DNA from degeneration by nuclease, has been widely studied in gene delivery. Höbel et al ${ }^{11}$ established the therapeutic efficacy and safety of PEI F25-LMW/siRNAmediated knockdown of VEGF in tumor cells. The results showed that PEI F25-LMW/siRNA complexes, which can be stored frozen as opposed to many other carriers, represent an efficient, safe, and promising modality in antitumor therapy. Modification of PEI with several functional moieties revealed that PEI succinylation resulted in up to a 10 -fold reduction of polymer toxicity compared with unmodified PEI. Moreover, succinylated PEI/siRNA complexes were able to induce remarkable knockdown of the target luciferase gene at the lowest tested siRNA concentration. ${ }^{52}$

In the study by Wang, ${ }^{53}$ TAT-conjugated PEGylated magnetic polymeric liposomes (TAT-PEG-MPLs) formed with superparamagnetic nanoparticles and TAT were successfully prepared and evaluated in vitro and in vivo. The results indicated that TAT-PEG-MPLs were spherical and nonaggregated in solution, with significantly small mean diameters $(83.2 \mathrm{~nm})$ and high magnetization. In cell penetration tests performed through fluorescein isothiocyanate (FITC) labeling, the uptake of TAT-PEG-MPLs by MCF-7 cells was greater than that of PEG-MPLs. Most importantly, in vivo animal experiment, MRI, histological analysis, and atomic absorption spectrophotometry revealed that TAT-PEG-MPLs nanoparticles significantly accumulated around the target site, and even inside nerve cells.

PLGA is an amorphous polymer, with molecular weights ranging from 5000-300,000. It can be used as medical film and carrier material for sustained-release dosage systems, with lower toxicity, less irritation, and minimal inflammatory responses. Luo et $\mathrm{al}^{54}$ incorporated the siRNA sequence of the methyl-CpG binding domain protein 1 (MBD1) plasmid into a PLGA-poloxamer carrier to test the therapeutic effect of this compound on BxPC-3 human pancreatic cancer cells. They found that the PLGA-poloxamer carriers can successfully transfect the MBD1 siRNA plasmid into tumor cells and that the PLGA-MBD1 nanoparticle compound can inhibit cell growth and induce apoptosis.

Katas et $\mathrm{al}^{55}$ incorporated PEI into PLGA particles to produce spherical, positively charged nanoparticles that are able to protect siRNA against nuclease degradation. Cell culture studies showed that PLGA-PEI nanoparticles with encapsulated siRNA are more efficient in silencing the targeted gene than PEI alone, with certain biocompatibility.

Ladeira et $\mathrm{al}^{56}$ described a novel approach to siRNA delivery by single-walled carbon nanotubes. In the study, the siRNA delivery system showed nonspecific toxicity and transfection efficiency greater than $95 \%$. This approach offers the potential for siRNA delivery into different types of cells, including hardto-transfect cells such as neuronal cells and cardiomyocytes. 
Gold nanoparticles/nanorods (GNPs/GNRs) have the distinct advantage of being easily modified. Hence, with their positively charged surfaces, GNPs/GNRs can easily attach to negatively charged siRNA. Bonoiu et $\mathrm{al}^{57}$ applied GNRs as siRNA delivery to explore the dopaminergic brain signaling pathway in vitro. Gene silencing in these cells was evident, with no observed cytotoxicity. Moreover, these nanoplexes can transmigrate across the model of the blood-brain barrier. However, reports about GNPs as gene carriers are rare.

Nevertheless, research regarding siRNA delivery was inspired by the molecular machinery within the phi29 bacteriophage DNA packaging motor, which contains six copies of packaging RNA (pRNA) molecules that form a hexameric ring, which is the crucial part of the motor. ${ }^{58}$ Utilizing the novel properties of this pRNA, we constructed pRNA dimers and trimers with potential to serve as parts in nanotechnology. pRNA-derived nanoparticles have small sizes (20-40 nm), making them particularly suited for in vivo systemic delivery; the optimal size range for cell uptake is $10-100 \mathrm{~nm} .{ }^{59}$ Tarapore et al ${ }^{60}$ explored the potential of pRNA as a vehicle in carrying siRNA to target metallothionein-IIa (MT-IIA) messenger RNA (mRNA) specifically. They found that $\mathrm{pRNA}$ chimeras targeting MTIIA are localized within the GW/P-bodies, and are more potent than siRNA alone in silencing MT-IIA expression. Therefore, the pRNA system, which can assemble into multivalent nanoparticles, has great potential as a highly potent therapeutic agent.

\section{Targeted siRNA delivery system}

Targeted RNAi therapy is a relatively new approach that can be used to silence genes reversibly in vivo by selective targeting. Targeting the diseased cell, organ, or tissue will increase the silencing potency of a given dose of siRNA. Specific cell targeting will also prevent side effects by avoiding nondiseased cells. ${ }^{13}$ Aptamers, antibodies, small peptides, and other ligands that bind to the signature molecules with high specificity and affinity have been studied extensively for their ability to guide siRNA to the target tissues and cells. ${ }^{47}$

Dickerson et $\mathrm{al}^{61}$ designed nanoparticles functionalized with peptides that specially target the erythropoietin-producing hepatocellular (Eph) A2 receptor to deliver siRNAs targeting epidermal growth factor receptor (EGFR). The results showed that the nanoparticles decreased EGFR expression levels and significantly increased the sensitivity of this cell line to docetaxel. Agrawal et al ${ }^{62}$ designed dendrimer-conjugated magnetofluorescent nanoworms called "dendriworms" as a modular platform for siRNA delivery in vivo. Their study showed that dendriworms carrying siRNA against EGFR reduced EGFR protein levels in human glioblastoma cells by $70 \%-80 \%$; anti-EGFR dendriworms led to specific and significant suppression of EGFR expression.

The folate receptor is also an important target for anticancer drug delivery. Many anticancer drugs, such as prodrugenzymes, toxic proteins, liposome drugs, and nucleic acid molecules, including siRNA, can be combined with folic acid to achieve target specificity. For example, liposome-wrapped siRNA nanoparticles can be modified with folic acid to inhibit the growth of a targeted tumor. ${ }^{63}$

Aptamers are oligonucleic acid or peptide molecules that are normally selected from a large random sequence pool to bind to a specific target molecule. Chimeric RNA molecules that contain an RNA aptamer directly linked to the passenger strand of siRNA can be transcribed in vitro and readily purified in large quantities. Therefore, aptamers can enhance the ability of siRNAs to target different cells. To date, only a couple of aptamers have been harnessed for targeted siRNA delivery to specific cell populations. Some studies have shown enhancement of target gene silencing activity and specificity using aptamer-siRNA chimeras. Furthermore, anti-tumor activity is further enhanced by appending a polyethylene glycol moiety, which increases the circulating half-life of the chimeras. ${ }^{64}$

\section{Other delivery systems}

Lee et $\mathrm{a}^{65}$ developed pluronic/polyethylenimine shell crosslinked nanocapsules with embedded magnetite nanocrystals (PPMCs) for magnetically triggered delivery of siRNA. PPMC/siRNA-PEG complexes were efficiently taken up by cancer cells upon exposure to a magnet, thereby enhancing intracellular uptake and the silencing effect of siRNA. The study suggests that these novel nanomaterials could be potentially utilized as magnetically triggered delivery of various nucleic acid-based therapeutic agents.

Recently, ultrasound-mediated gene delivery with nanoand microbubbles was developed as a novel nonviral vector system. This system can directly deliver plasmid DNA and siRNA into the cytosol without endocytosis. Therefore, these genes are able to escape lysosomal degradation, resulting in enhanced gene expression efficiency. ${ }^{66,67}$ Zhou et al ${ }^{68}$ transfected plasmid DNA of pigment epithelial derived factor (PEDF) into human retinal pigment epithelial (hRPE) cells and choroidal neovascularization (CNV) animal models by ultrasound-mediated microbubbles. The results showed that 
microbubbles with ultrasound irradiation could significantly enhance PEDF delivery compared with microbubbles or ultrasound alone, and that the $\mathrm{CNV}$ of rats was inhibited effectively.

\section{Limitations and other side-effects of siRNA delivery}

siRNA is easily degraded by enzymes in blood, tissues, and cells. Several types of chemically modified siRNA have been produced and investigated to improve stability; however, target site accumulation after administration is still extremely low, even when stability is improved. ${ }^{69}$ Moreover, the cost and safety of these formulations must also be considered, ${ }^{70}$ and many groups have found that large numbers of 2'-O-Me modifications (in either strand) decrease siRNA activity. ${ }^{71-73}$

Even though an increasing number of cationic liposomes are used as nonviral-based gene vectors, studies have demonstrated that these liposomes still cause significant toxicity, ${ }^{74,75}$ such as cell contraction, mitotic inhibition, formation of aggregates in blood, and the tendency to induce inflammatory response. Some researchers have been trying to design new liposomal structures to reduce their cytotoxicity, and found that modifying the cationic liposome structure can be an effective strategy for controlling its toxicity. ${ }^{76}$ Hundreds of lipids share the common structure of a positively charged hydrophilic head and hydrophobic tail that are connected via a linker structure. Most of the linkages between the hydrophilic and hydrophobic moieties are ether, ester, carbamate, or amide bonds that can affect the rate of biodegradation..$^{77}$ Moreover, their transfection efficiency needs further improvement for in vivo application.

Aside from studies of its efficacy, some researchers investigated the biosafety and toxicity issues of chitosan. A recent study by Chellat et $\mathrm{al}^{78}$ found that high chitosan/DNA nanoparticle concentrations do not induce macrophage secretion of tumor necrosis factor (TNF)- $\alpha$, interleukin (IL)- $1 \beta$, IL-6, and IL-10, which showed that nanoparticles have no evident inflammatory activity. The toxicity of chitosan can be reduced by modification with the nontoxic and biocompatible acrylic imidazole, and additional modifications of the nanoparticle components helpfully reduce toxicity and increase transfection efficiency. ${ }^{79}$ Dabold et a ${ }^{80}$ reported that the in vitro toxicity of liposome-chitosan nanoparticle complexes (LCS-NP) in the conjunctival epithelial cell (CEC) line was very low. LCS-NPs were identified inside CECs after 15 minutes and inside primary cultures of CECs after 30 minutes.
Watari et $\mathrm{l}^{81}$ revealed the micro/nanosizing effect of materials on living organisms. Various sizes of particles, from $500 \mathrm{~nm}$ to $150 \mu \mathrm{m}$, were used to co-culture with human neutrophils, which play a central role in the initial stage of inflammation against foreign bodies, as probe cells. Particles were also inserted into the subcutaneous connective tissue in the abdominal region of Wistar rats. The results showed that: 1) the toxicity level, shown as an absolute intensity of superoxide production, as well as the expression of cytokines IL-1 $\beta$ and TNF- $\alpha$ by micro/nanoparticles is very low; 2 ) the reaction is nonspecific and any particle below cell size are regarded by cells as a foreign object, including neutrophils and macrophages; and 3) for the materials as implants, there is no strong rejection and it is, therefore, generally acceptable to any person.

However, other researchers reported different results. Nanoscale gene vectors, after being transfected into the body as exogenous materials, are taken up by the reticuloendothelial mononuclear phagocytic system, which is mainly concentrated in the spleen, liver, lungs, bone marrow, and lymph nodes. The nanoparticles could be retained in the tissues for over 30 days; therefore, if not effectively removed, accumulation of the nanosized vectors could lead to certain organ damage..$^{82-84}$

Low immunogenicity is one of the unique characteristics of nonviral gene vectors. However, studies have shown that the DNA-cationic liposome complex (lipoplex) systemic drugs can activate the innate immune system. ${ }^{85}$ Sakurai et a ${ }^{86}$ found that the administration of lipoplex produces a greater amount of inflammatory cytokines, such as IL-6, IL-12, and TNF- $\alpha$, than adenovirus vector administration. On the other hand, chitosan/DNA nanoparticles and single-walled carbon nanotubes are not available for immune stimulation..$^{87-89}$

\section{Clinical trials}

From the first in vivo evidence of RNAi-based therapeutic efficacy in an animal disease model in $2003,{ }^{90}$ the pace of its drug development has been rapid. Most of the clinical trials approved by the FDA are nontargeted, designed for intravitreal injection or inhalation to cure age-related macular degeneration (AMD), a leading cause of blindness, or respiratory syncytial virus (RSV), the leading cause of pediatric hospitalizations in the United States today. These trials with naked siRNA have shown certain results without untoward toxicity. ${ }^{14,91}$

Multiple nanoparticle formulations of siRNA for oncology are currently under clinical development. ${ }^{92}$ The first targeted-delivery siRNA therapeutic agent approved by the US Food and Drug Administration (FDA) is CALAA-01, a PEGylated, transferrin-targeted nanoparticle that can combine siRNA molecule with the transferrin receptor on 
the tumor cell surface. This is currently being investigated clinically in patients with solid cancers in the United States. ${ }^{93}$ The results demonstrate that the siRNA nanoparticles are able to provide transient inhibition of tumor growth.

Atu027 is a liposomal formulation of siRNA against protein kinase N3, developed by Silence Therapeutics AG, and is currently being investigated in Phase I clinical trials in Germany. ${ }^{94}$ Atu027 comprises neutral fusogenic and PEGmodified lipid components with improved pharmacokinetic properties, cellular uptake, and efficient siRNA release from endosomes after endocytosis. ${ }^{95}$

ALN-VSP, a nontargeted liposomal formulation of two siRNAs targeting kinesin spindle protein and VEGF, is in clinical development in the United States for the treatment of liver cancers. Due to interests in the potent, promising, and novel siRNAs and the need to protect them from degradation within the circulation, interest and research into nanoparticle formulations of nucleic acids is likely to grow continually. ${ }^{92}$

\section{Perspective of nonviral vector}

siRNA technology, which is attracting much interest in the research community, holds great promise as a therapeutic intervention for targeted gene silencing in cancers and other diseases. Several siRNA-based therapeutic agents are already in clinical trials. Further development of siRNA therapy depends on the development of safe and effective carriers for systemic administration. As described in the present study, cationic nanoparticles have emerged as one of the most attractive carriers because of their ability to form complexes with negatively charged siRNA and their high transfection efficiency. As a whole, the transfection efficiency reported thus far for nonviral approaches is still below that of the highly efficient viral vectors. Further improvements to increase the efficiency and reduce the toxicity of nonviral vectors are needed before their clinical significance can be maximized. Therefore, to achieve more efficient, long-lasting, and nontoxic gene delivery vectors, optimized delivery systems still have many challenges to overcome.

\section{Acknowlegment}

This subject was supported by fund of Key Project of Tianjin Medical University (2009XK20).

\section{Disclosure}

The authors report no conflicts of interest in this work.

\section{References}

1. Fire A, Xu S, Montgomery MK, Kostas SA, Driver SE, Mello CC. Potent and specific genetic interference by doublestranded RNA in Caenorhabditis elegans. Nature. 1998;391(6669):806-811.
2. Turchinovich A, Zoidl G, Dermietzel R. Non-viral siRNA delivery into the mouse retina in vivo. BMC Ophthalmology. 2010;10(25): 1471-1475.

3. Leung RK, Whittaker PA. RNA interference: from gene silencing to gene-specific therapeutics. Pharmacol Ther. 2005;107(2):222-239.

4. Elbashir SM, Harborth J, Lendeckel W, Yalcin A, Weber K, Tuschl T. Duplexes of 21-nucleotide RNAs mediate RNA interference in cultured mammalian cells. Nature. 2001;411(6836):494-498.

5. Bumcrot D, Manoharan M, Koteliansky V, Sah DW. RNAi therapeutics: a potential new class of pharmaceutical drugs. Nat Chem Biol. 2006; 2(12):711-719.

6. Zamore PD, Tuschl T, Sharp PA, Bartel DP. RNAi: doublestranded RNA directs the ATP-dependent cleavage of mRNA at 21-23 nucleotide intervals. Cell. 2000;101(1):25-33.

7. Parrish S, Fleenor J, Xu S, Mello C, Fire A. Functional anatomy of a dsRNA trigger: differential requirement for the two trigger strands in RNA interference. Mol Cell. 2000;6(5):1077-1087.

8. Guo B, Zhang Y, Luo G, Li L, Zhang J. Lentivirus-mediated small interfering RNA targeting VEGF-C inhibited tumor lymphangiogenesis and growth in breast carcinoma. Anat Rec (Hoboken). 2009 May; 292(5):633-639.

9. Chen C, Sun J, Liu G, Chen J. Effect of small interference RNA targeting HIF-1alpha mediated by rAAV combined L: -ascorbate on pancreatic tumors in athymic mice. Pathol Oncol Res. 2009;15(1):109-114.

10. Gao YS, Mei J, Tong TL, Hu M, Xue HM, Cai XS. Inhibitory effects of VEGF-siRNA mediated by adenovirus on osteosarcoma-bearing nude mice. Cancer Biother Radiopharm. 2009;24(2):243-247.

11. Höbel S, Koburger I, John M, et al. Polyethylenimine/small interfering RNA-mediated knockdown of vascular endothelial growth factor in vivo exerts anti-tumor effects synergistically with Bevacizumab. J Gene Med. 2010;12(3):287-300.

12. Zuhorn IS, Engberts JB, Hoekstra D. Gene delivery by cationic lipid vectors: overcoming cellular barriers. Eur Biophys J. 2007;36:349-362.

13. Pirollo KF, Chang EH. Targeted delivery of small interfering RNA: approaching effective cancer therapies. Cancer Res. 2008;68: $1247-1250$.

14. Wang Y, Li Z, Han Y, Liang LH, Ji A. Nanoparticle-based delivery system for application of siRNA in vivo. Curr Drug Metab. 2010;11(2): 182-196.

15. Choung S, Kim YJ, Kim S, Park HO, Choi YC. Chemical modification of siRNAs to improve serum stability without loss of efficacy. Biochem Biophys Res Commun. 2006;342(3):919-927.

16. Mook OR, Baas F, de Wissel MB, Fluiter K. Evaluation of locked nucleic acid-modified small interfering RNA in vitro and in vivo. Mol Cancer Ther. 2007;6(3):833-843.

17. Ui-Tei K, Naito Y, Zenno S, et al. Functional dissection of siRNA sequence by systematic DNA substitution: modified siRNA with a DNA seed arm is a powerful tool for mammalian gene silencing with significantly reduced off-target effect. Nucleic Acids Res. 2008;36(7): 2136-2151.

18. Bramsen JB, Laursen MB, Nielsen AF, et al. A large-scale chemical modification screen identifies design rules to generate siRNAs with high activity, high stability and low toxicity. Nucleic Acids Res. 2009;37(9): 2867-2881.

19. Chiu YL, Rana TM. siRNA function in RNAi: a chemical modification analysis. RNA. 2003;9(9):1034-1048.

20. Pieken WA, Olsen DB, Benseler F, Aurup H, Eckstein F. Kinetic characterization of ribonucleaseresistant $2^{\prime}$-modified hammerhead ribozymes. Science. 1991;253:314-317.

21. Layzer JM, McCaffrey AP, Tanner AK, Huang Z, Kay MA, Sullenger BA. In vivo activity of nuclease-resistant siRNAs. $R N A$. 2004;10:766-771.

22. Jackson AL, Burchard J, Leake D, et al. Position-specific chemical modification of siRNAs reduces "off-target" transcript silencing. RNA. 2006;12:1197-1205.

23. Gaglione M, Messere A. Recent progress in chemically modified siRNAs. Mini Rev Med Chem. 2010;10:578-595. 
24. Overhoff M, Sczakiel G. Phosphorothioate-stimulated uptake of short interfering RNA by human cells. EMBO Rep. 2005;6(12):1176-1181.

25. Hall AH, Wan J, Shaughnessy EE, Ramsay Shaw B, Alexander KA. RNA interference using boranophosphate siRNAs: structure-activity relationships. Nucleic Acids Res. 2004;32(20):5991-6000.

26. Behlke MA. Chemical modification of siRNAs for in vivo use. Oligonucleotides. 2008;18(4):305-319.

27. Terrazas M, Kool ET. RNA major groove modifications improve siRNA stability and biological activity. Nucleic Acids Res. 2009;37(2):346-353.

28. Chiu YL, Ali A, Chu CY, Cao H, Rana TM. Visualizing a correlation between siRNA localization, cellular uptake, and RNAi in living cells. Chem Biol. 2004;11(8):1165-1175.

29. Lorenz C, Hadwiger P, John M, Vornlocher HP, Unverzagt C. Steroid and lipid conjugates of siRNAs to enhance cellular uptake and gene silencing in liver cells. Bioorg Med Chem Lett. 2004;14:4975-4977.

30. Soutschek J, Akinc A, Bramlage B, et al. Therapeutic silencing of an endogenous gene by systemic administration of modified siRNAs. Nature. 2004;432:173-178.

31. Behlke MA. Chemical modification of siRNAs for in vivo use. Oligonucleotides. 2008;18(4):305-319.

32. Watts JK, Deleavey GF, Damha MJ. Chemically modified siRNA: tools and applications. Drug Discov Today. 2008;13:842-856.

33. Soriano P, Dijkstra J, Legrand A, et al. Targeted and nontargeted liposomes for in vivo transfer to rat liver cells of a plasmid containing the preproinsulin I gene. Proc Natl Acad Sci U S A. 1983;80(23):7128-7131.

34. De Fougerolles A, Vornlocher HP, Maraganore J, Lieberman J. Interfering with disease: a progress report on siRNA-based therapeutics. Nat Rev Drug Discov. 2007;6(6):443-453.

35. Li J, Chen YC, Tseng YC, Mozumdar S, Huang L. Biodegradable calcium phosphate nanoparticle with lipid coating for systemic siRNA delivery. J Control Release. 2010;142(3):416-421.

36. Barichello JM, Ishida T, Kiwada H. Complexation of siRNA and pDNA with cationic liposomes: the important aspects in lipoplex preparation. Methods Mol Biol. 2010;605:461-472.

37. Spagnou S, Miller AD, Keller M. Lipidic carriers of siRNA: differences in the formulation, cellular uptake, and delivery with plasmid DNA. Biochemistry. 2004;43(42):13348-13356.

38. Peer D, Park EJ, Morishita Y, Carman CV, Shimaoka M. Systemic leukocyte-directed siRNA delivery revealing cyclin D1 as an antiinflammatory target. Science. 2008;319(5863):627-630.

39. Halder J, Kamat AA, Landen CN Jr, et al. Focal adhesion kinase targeting using in vivo short interfering RNA delivery in neutral liposomes for ovarian carcinoma therapy. Clin Cancer Res. 2006;12(16):4916-4924.

40. Felgner PL, Ringold GM. Cationic liposome-mediated transfection. Nature. 1989;337(6205):387-388.

41. Zhang C, Tang N, Liu X, Liang W, Xu W, Torchilin VP. siRNAcontaining liposomes modified with polyarginine effectively silence the targeted gene. J Control Release. 2006;112:229-239.

42. Leal C, Bouxsein NF, Ewert KK, Safinya CR. Highly efficient gene silencing activity of siRNA embedded in a nanostructured gyroid cubic lipid matrix. J Am Chem Soc. 2010;132(47):16841-16847.

43. Kim WJ, Kim SW. Efficient siRNA delivery with non-viral polymeric vehicles. Pharm Res. 2009;26(3):657-666.

44. Huang AJ. Suppression of keratoepithelin and myocilin by small interfering RNA (an American Ophthalmological Society thesis). Trans Am Ophthalmol Soc. 2007;105:365-378.

45. Kim WJ, Chang CW, Lee M, Kim SW. Efficient siRNA delivery using water soluble lipopolymer for anti-angiogenic gene therapy. $J$ Control Release. 2007;118(3):357-363.

46. Pirollo KF, Rait A, Zhou Q, et al. Materializing the potential of small interfering RNA via a tumor-targeting nanodelivery system. Cancer Res. 2007;67(7):2938-2943.

47. Guo P, Coban O, Snead NM, et al. Engineering RNA for targeted siRNA delivery and medical application. Adv Drug Deliv Rev. 2010; 62(6):650-666.
48. Kim DH, Kang JW, Kim TR, Kim EJ, Im JS, Kim J. A polyol-mediated synthesis of titania-based nanoparticles and their electrochemical properties. J Nanosci Nanotechnol. 2007;7(11):3954-3958.

49. Kim BH, Cho MS, Kim SY, et al. Dry sol-gel polycondensation of hydrosilanes to organosilicas catalyzed by colloidal nickel nanoparticles. J Nanosci Nanotechnol. 2007;7(11):3964-3968.

50. Howard KA, Rahbek UL, Liu X, et al. RNA interference in vitro and in vivo using a novel chitosan/siRNA nanoparticle system. Mol Ther. 2006;14(4):476-484.

51. Ghosn B, Singh A, Li M, et al. Efficient gene silencing in lungs and liver using imidazole-modified chitosan as a nanocarrier for small interfering RNA. Oligonucleotides. 2010;20(3):163-172.

52. Zintchenko A, Philipp A, Dehshahri A, Wagner E. Simple modifications of branched PEI lead to highly efficient siRNA carriers with low toxicity. Bioconjug Chem. 2008;19(7):1448-1455.

53. Wang HJ, Zhang SG, Liao ZY, et al. PEGlated magnetic polymeric liposome anchored with TAT for delivery of drugs across the bloodspinal cord barrier. Biomaterials. 2010;31(25):6589-6596.

54. Luo G, Jin C, Long J, et al. RNA interference of MBD1 in BxPC-3 human pancreatic cancer cells delivered by PLGA-poloxamer nanoparticles. Cancer Biol Ther. 2009;8(7):594-598.

55. Katas H, Cevher E, Alpar HO. Preparation of polyethyleneimine incorporated poly (D,L-lactide-co-glycolide) nanoparticles by spontaneous emulsion diffusion method for small interfering RNA delivery. Int J Pharm. 2009;369(1-2):144-154.

56. Ladeira MS, Andrade VA, Gomes ER, et al. Highly efficient siRNA delivery system into human and murine cells using single-wall carbon nanotubes. Nanotechnology. 2010;21(38):385101.

57. Bonoiu AC, Mahajan SD, Ding H, et al. Nanotechnology approach for drug addiction therapy: gene silencing using delivery of gold nanorodsiRNA nanoplex in dopaminergic neurons. Proc Natl Acad Sci U S A. 2009; 106(14):5546-5550

58. Guo S, Tschammer N, Mohammed S, Guo P. Specific delivery of therapeutic RNAs to cancer cells via the dimerization mechanism of phi29 motor pRNA. Hum Gene Ther. 2005;16(9):1097-1109.

59. Shu D, Moll WD, Deng Z, Mao C, Guo P. Bottom-up assembly of RNA arrays and superstructures as potential parts in nanotechnology. Nano Lett. 2004;4(9):1717-1723.

60. Tarapore P, Shu Y, Guo P, Ho SM. Application of Phi29 motor pRNA for targeted therapeutic delivery of siRNA silencing metallothionein-IIA and survivin in ovarian cancers. Mol Ther. 2011;19(2):386-394.

61. Dickerson EB, Blackburn WH, Smith MH, Kapa LB, Lyon LA, McDonald JF. Chemosensitization of cancer cells by siRNA using targeted nanogel delivery. BMC Cancer. 2010;10:1-11.

62. Agrawal A, Min DH, Singh N, et al. Functional delivery of siRNA in mice using dendriworms. ACS Nano. 2009;9(3):2495-2504.

63. Yoshizawa T, Hattori Y, Hakoshima M, Koga K, Maitani Y. Folatelinked lipid-based nanoparticles for synthetic siRNA delivery in $\mathrm{KB}$ tumor xenografts. Eur J Pharm Biopharm. 2008;70(3):718-725.

64. Dassie JP, Liu XY, Thomas GS, et al. Systemic administration of optimized aptamer-siRNA chimeras promotes regression of PSMAexpressing tumors. Nat Biotechnol. 2009;27(9):839-849.

65. Lee K, Bae KH, Lee Y, Lee SH, Ahn CH, Park TG. Pluronic/ polyethylenimine shell crosslinked nanocapsules with embedded magnetite nanocrystals for magnetically triggered delivery of siRNA. Macromol Biosci. 2010;10(3):239-245.

66. Suzuki R, Oda Y, Utoguchi N, Maruyama K. Progress in the development of ultrasound-mediated gene delivery systems utilizing nano- and microbubbles. J Control Release. 2011;149(1):36-41.

67. Hernot S, Klibanov AL. Microbubbles in ultrasound-triggered drug and gene delivery. Adv Drug Deliv Rev. 2008;60(10):1153-1166.

68. Zhou XY, Liao Q, Pu YM, et al. Ultrasound-mediated microbubble delivery of pigment epithelium-derived factor gene into retina inhibits choroidal neovascularization. Chin Med J (Engl). 2009;122(22):2711-2717.

69. Higuchi Y, Kawakami S, Hashida M. Strategies for in vivo delivery of siRNAs: recent progress. BioDrugs. 2010;24(3):195-205. 
70. Manoharan M. RNA interference and chemically modified siRNAs. Nucleic Acids Res Suppl. 2003;3:115-116.

71. Chiu YL, Rana TM. siRNA function in RNAi: a chemical modification analysis. RNA. 2003;9:1034-1048.

72. Braasch DA, Jensen S, Liu Y, et al. RNA interference in mammalian cells by chemically modified RNA. Biochemistry. 2003;42:7967-7975.

73. Czauderna F, Fechtner M, Dames S, et al. Structural variations and stabilising modifications of synthetic siRNAs in mammalian cells. Nucl Acids Res. 2003;31:2705-2716.

74. Stewart MJ, Plautz GE, Del Buono L, et al. Gene transfer in vivo with DNA-liposome complexes: safety and acute toxicity in mice. Hum Gene Ther. 1992;3(3):267-275.

75. Filion MC, Philips NC. Major limitations in the use of cationic liposomes for DNA delivery. Int J Pharm. 1998;162(1):159-170.

76. Aberle AM, Tablin F, Zhu J, Walker NJ, Gruenert DC, Nantz MH A novel tetraester construct that reduces cationic lipid-associated cytotoxicity. Implications for the onset of cytotoxicity. Biochemistry. 1998;37(18):6533-6540.

77. Al-Dosari MS, Gao X. Nonviral gene delivery: principle, limitations, and recent progress. AAPS J. 2009;11(4):671-681.

78. Chellat F, Grandjean-Laquerriere A, Le Naour R, et al. Metalloproteinase and cytokine production by THP-1 macrophages following exposure to chitosan-DNA nanoparticles. Biomaterials. 2005;26(9):961-970.

79. Kim TH, Ihm JE, Choi YJ, Nah JW, Cho CS. Efficient gene delivery by urocanic acid-modified chitosan. J Control Release. 2003;93(3):389-402.

80. Diebold Y, Jarrín M, Sáez V, et al. Ocular drug delivery by liposomechitosan nanoparticle complexes (LCS-NP). Biomaterials. 2007;28(8): $1553-1564$.

81. Watari F, Takashi N, Yokoyama A, et al. Material nanosizing effect on living organisms: non-specific, biointeractive, physical size effects. $J$ R Soc Interface. 2009;6(Suppl 3):S371-S388.

82. Cho M, Cho WS, Choi M, et al. The impact of size on tissue distribution and elimination by single intravenous injection of silica nanoparticles. Toxicol Lett. 2009;189(3):177-183.

83. Tang J, Xiong L, Wang S, et al. Distribution, translocation and accumulation of silver nanoparticles in rats. $J$ Nanosci Nanotechnol. 2009;9(8):4924-4932.
84. Xie G, Sun J, Zhong G, Shi L, Zhang D. Biodistribution and toxicity of intravenously administered silica nanoparticles in mice. Arch Toxicol. 2010;84:183-190.

85. Ushitora M, Sakurai F, Yamaguchi T, et al. Prevention of hepatic ischemia-reperfusion injury by pre-administration of catalaseexpressing adenovirus vectors. J Control Release. 2010;142(3): 431-437.

86. Sakurai H, Kawabata K, Sakurai F, Nakagawa S, Mizuguchi H. Innate immune response induced by gene delivery vectors. Int J Pharm. 2008;354(1-2):9-15.

87. Chellat F, Grandjean-Laquerriere A, Le Naour R, et al. Metalloproteinase and cytokine production by THP-1 macrophages following exposure to chitosan-DNA nanoparticles. Biomaterials. 2005;26(9):961-970.

88. Lam CW, James JT, McCluskey R, Hunter RL. Pulmonary toxicity of single-wall carbon nanotubes in mice 7 and 90 days after intratracheal instillation. Toxicol Sci. 2004;77(1):126-134.

89. Ditto AJ, Shah PN, Yun YH. Non-viral gene delivery using nanoparticles. Expert Opin Drug Deliv. 2009;6(11):1149-1160.

90. Song E, Lee SK, Wang J, et al. RNA interference targeting Fas protects mice from fulminant hepatitis. Nature Med. 2003;9:347-351.

91. DeVincenzo J, Lambkin-Williams R, Wilkinson T, et al. A randomized, double-blind, placebo-controlled study of an RNAi-based therapy directed against respiratory syncytial virus. PNAS. 2010;107(19): 8800-8805.

92. Heidel JD, Davis ME. Clinical developments in nanotechnology for cancer therapy. Pharm Res. 2011;28:187-199.

93. Davis ME. The first targeted delivery of siRNA in humans via a selfassembling, cyclodextrin polymer-based nanoparticle: from concept to clinic. Mol Pharm. 2009;6:659-668.

94. Aleku M, Schulz P, Keil O, et al. Atu027, a liposomal small interfering RNA formulation targeting protein kinase N3, inhibits cancer progression. Cancer Res. 2008;68(23):9788-9798.

95. Santel A, Aleku M, Keil O, et al. A novel siRNA-lipoplex technology for RNA interference in the mouse vascular endothelium. Gene Ther 2006;13(16):1222-1234.
International Journal of Nanomedicine

\section{Publish your work in this journal}

The International Journal of Nanomedicine is an international, peerreviewed journal focusing on the application of nanotechnology in diagnostics, therapeutics, and drug delivery systems throughou the biomedical field. This journal is indexed on PubMed Central, MedLine, CAS, SciSearch ${ }^{\circledR}$, Current Contents $₫ /$ Clinical Medicine,

\section{Dovepress}

Journal Citation Reports/Science Edition, EMBase, Scopus and the Elsevier Bibliographic databases. The manuscript management system is completely online and includes a very quick and fair peer-review system, which is all easy to use. Visit http://www.dovepress.com/ testimonials.php to read real quotes from published authors. 